\title{
A needs assessment for a master's program in dental public health in Jeddah Saudi Arabia
}

This article was published in the following Dove Press journal:

Advances in Medical Education and Practice

29 March 2013

Number of times this article has been viewed

\author{
Dania E Al Agili \\ Department of Preventive Dental \\ Sciences, Faculty of Dentistry, \\ King Abdulaziz University, Jeddah, \\ Saudi Arabia
}

Correspondence: Dania Ebrahim Al Agili Department of Preventive Dental Sciences, Faculty of Dentistry, King Abdulaziz University, 80209, Jeddah 21589, Saudi Arabia

Tel +9662640344322267

Fax +96 6264033 I 6

Email dalagili@kau.edu.sa.com
Objectives: The Faculty of Dentistry at King Abdulaziz University in Jeddah, Saudi Arabia, is planning a master's program in dental public health (DPH) to address the lack of adequate DPH professionals in the country. A needs assessment survey or situational analysis is typically recommended as the foundation of any curriculum development process. We conducted this survey to understand the level of DPH expertise existing in the country, to identify needs and gaps, and to explore perceptions in the area of DPH.

Methods: A DPH competency based survey was emailed to all onsite Saudi faculty members, all DPH practitioners in Jeddah city, and a random sample of dental interns $(n=122)$. The questionnaire collected information about participants' demographics, knowledge of DPH, preferred method for gaining knowledge about DPH, perceptions about a new master's program in $\mathrm{DPH}$, preferred teaching and delivery methods, prerequisite education, and self-assessment of participants' own DPH competency levels. Descriptive statistics, chi-square or Fisher's exact statistics, and proportional odds ratios were calculated to analyze data.

Results: There was a total of 105 respondents (86.1\%). About $98 \%$ had some knowledge of DPH. The most preferred method to gain knowledge on DPH was seminar series (47.6\%). The most preferred methods for teaching instruction were using a "list of discussion topics" and "providing examples," and the most preferred method for delivery of coursework was "face-to-face classroom activities with online readings and assignments." The most preferred prerequisite education was having a bachelor's degree in dentistry. Most participants considered themselves as having moderate experience and basic range of knowledge of DPH practices and competencies.

Conclusion: The survey has helped assess the participants' views on the need for a graduate program in DPH. It is a preliminary step in designing a well-structured program, which will address the needs and gaps in oral public health in the country and inform the development of course content.

Keywords: needs assessment, situational analysis, education, dental public health

\section{Background}

Dental public health (DPH) is defined by the American Board of Dental Public Health as:

$[\ldots]$ the science and art of preventing and controlling dental diseases and promoting dental health through organized community efforts. It is that form of dental practice which serves the community as a patient rather than the individual. It is concerned with the dental education of the public, with applied dental research, and with the administration of group dental care programs as well as the prevention and control of dental diseases on a community basis. ${ }^{1}$ 
Public health dentists promote oral health by:

- assessing the oral health needs of the community;

- developing and implementing oral health policy; and

- providing programs and services that address oral health issues.

Many dentists work within public health settings to enhance the traditional DPH infrastructure. Many do so without formal public health training. These public health settings include, but are not limited to: city, provincial, and regional health departments; correctional facilities; nursing and other long-term care facilities for the elderly and those with various disabilities; school-based health programs; and free and/or volunteer clinics.

The Core Public Health Functions Steering Committee developed the framework for the Essential Services in 1994. ${ }^{2}$ This steering committee included representatives from the United States Public Health Service agencies and other major public health organizations. The following Essential Services provide a working definition of public health and a guiding framework for the responsibilities of local public health systems:

1. to monitor health status to identify and solve community health problems;

2. to diagnose and investigate health problems and health hazards in the community;

3. to inform, educate, and empower people about health issues;

4. to mobilize community partnerships and actions to identify and solve health problems;

5. to develop policies and plans that support individual and community health efforts;

6. to enforce laws and regulations that protect health and ensure safety;

7. to link people to needed personal health services and assure the provision of health care when otherwise unavailable;

8. to assure competent public and personal health care workforce;

9. to evaluate effectiveness, accessibility, and quality of personal and population-based health services;

10. and to research for new insights and innovative solutions to health problems.

The Faculty of Dentistry at King Abdulaziz University (KAUFD) is planning a master's program in DPH to address the lack of adequate DPH professionals in the country. In order to design a comprehensive program, it is essential to conduct needs assessment to understand the level of DPH expertise existing in the country, to identify needs and gaps, and to explore overall perception in the area of DPH.

A needs assessment or situational analysis is typically recommended as the foundation of any curriculum development process. ${ }^{3}$ Unlike the traditional approach to education where teachers determine what content needs to be learned, teach it, and then test to see if the content was learned, needs assessment is based on expected behavior; that is, "competencies." Competency-based training requires that educators and the stakeholders identify the necessary knowledge, skills, and behaviors as applied in real working conditions and settings. ${ }^{4}$ This will increase the likelihood that results will contribute to effective training that will raise performance levels. Additionally, needs assessments help identify existing resources or their lack thereof in the given setting that could be harnessed during the development and implementation of the curriculum. It is a powerful tool for clarifying and validating true needs that are necessary for making sound educational decisions. Therefore, integrating needs assessment throughout the curriculum development process can help assure that the program does not create an either/or situation, but rather benefits both the learners and the society. ${ }^{4}$

In 1997, The American Association of Public Health Dentistry (AAPHD) developed new competency statements and performance indicators for the specialty of DPH. These competencies help define the specialty and provide a base for educational curricula and the specialty board examination. ${ }^{5}$ The Centers for Disease Control and Prevention and the Association for Prevention Teaching and Research, in a published document entitled "Competencies-to-Curricula Toolkit," explain and emphasize the process of converting competencies into curriculum and training modalities. ${ }^{6}$ To move from competencies to curricula, the following steps are recommended: (1) specify the audience; (2) develop learning objectives; (3) assess the time availability of the learner; (4) determine how and when learning will be measured; (5) determine expected outcomes; (6) determine content and availability; (7) match teaching methods to the audience; (8) develop curriculum; and (9) evaluate the learner after the materials have been presented. ${ }^{6}$

We will use a similar approach in order to develop a competency-based curriculum that meets the goals and objectives of a DPH master's program, addresses them in the local context, and continually adapts them in response to institutional priorities and community needs. ${ }^{7}$ A needs assessment survey was conducted among Saudi dental professionals as an initial step to determine the need for DPH education. 


\section{Methods}

This study utilized a cross-sectional design to assess the needs for developing a master's program in DPH. The protocol of the study was approved by the Research Ethics Committee of the Faculty of Dentistry at KAUFD.

\section{Survey population}

All of the onsite Saudi faculty members $(n=83)$ at KAUFD, all Saudi DPH practitioners from outside KAUFD in the city of Jeddah $(n=5)$, and a random sample of 34 dental interns were included in the needs assessment survey. The survey was first emailed on May 30, 2012. Reminders were sent 2 weeks later. The survey was emailed again to nonresponders on September 1, 2012 and December 1, 2012. The collection of surveys was closed on December 27, 2012.

\section{Instrument}

A competency-based self-administered survey was designed (see Supplementary materials). Some of the survey questions were adapted and modified from questions in a paper published on the needs assessment of a graduate-level course on optical networking, ${ }^{8}$ and some were adapted from questions from Ghere et al. ${ }^{9}$ Other questions were added to address needs assessment specific to a DPH master's program.

The first part of the questionnaire collected information on demographics including age, gender, qualifications, current job titles, and specialization in dentistry. The second part of the questionnaire assessed the dental professionals' knowledge of DPH; perceptions about a new master's program in DPH; modes of delivery, and materials and strategies of teaching; and professionals' perceptions regarding the impact of a master's program on DPH in the country. We used a four-point Likert scale to score the responses. The scale ranged from 1 to 4 , where $1=$ strongly disagree, $2=$ disagree, $3=$ agree, and $4=$ strongly agree. In addition, the participants were asked to rank a list of skills, knowledge, or abilities most needed by DPH practitioners. A five-point Likert scale was used where $5=$ very important, $4=$ important, 3 = moderately important, 2 = of little importance, and $1=$ unimportant. The third and final part of the questionnaire asked the participants to self-assess their own competency level in DPH. We used a self-assessment rating scale (1-6) that has been validated and used extensively by Ghere et $\mathrm{al}^{9}$ in a "program evaluator competencies self-assessment tool," as part of professional development sessions, graduate-level seminars, and introductory program evaluation courses that conduct a self assessment. The list of skills and knowledge, as well as the core competencies for DPH were adopted from the competencies given by the AAPHD. The participants were asked to rank the importance of these competencies to their type of work using the five-point Likert scale where $5=$ very important, $4=$ important, $3=$ moderately important, $2=$ of little importance, and $1=$ unimportant.

\section{Data analysis}

The survey responses were entered in an Excel database (Microsoft Corporation, Redmond, WA, USA) and analyzed in SAS version 9.2 (SAS Institute Inc, Cary, NC, USA). The analysis began with descriptive statistics such as frequencies, percentages, and average scores for variables where appropriate. We compared response scores for questions on the preferred method to gain knowledge of DPH using a chi-square statistic or Fisher's exact test in cases where the numbers in the cells were less than five. The relationship between gender and age with responses for the preferred method of instruction, preferred method of delivery of instructions, and prerequisite education for DPH was evaluated. The participants were asked to check more than one preference for each option listed under these questions; thus, each option received an individual Likert score. Since the responses were ordinal, a proportional odds ratio was used for comparison. We also modeled self-competency scores across two age categories ( $<30$ and $\geq 30$ years) using proportional odds ratio. For the purpose of analysis we modeled the probability of being in a lower score category in the ordered value list (1 to 6 or 1 to 4 ). We used "male" as the referent category for gender, and the " $\geq 30$ " age group for the two age categories.

\section{Results}

A total of 105 persons responded to the survey. The overall response rate was $86.1 \%$. Among the respondents, 60 $(57.1 \%)$ were males and $45(42.9 \%)$ were females. The participants were almost equally distributed in three age categories; 47 (45.6\%) participants were less than 30 years, $26(25.2 \%)$ participants were between 30 and 40 years, and $30(29.1 \%)$ were more than 40 years of age. Based on their current position, the survey was comprised of 44 dental faculty (41.9\%), 20 demonstrators (20.4\%), 32 dental interns (30.5\%), seven consultants $(6.7 \%)$, one general practitioner $(0.9 \%)$, and one dental hygienist $(0.9 \%)$. We have reported only the primary appointments of all participants, but several participants held two positions. For example, a participant's primary appointment was as a dental faculty member, but he/she may also have been a private practitioner or a public health dentist. The qualifications of the participants included 
$50(47.6 \%)$ with a Bachelor of Dental Science, 23 (21.9\%) with a master's degree, $31(29.5 \%)$ with a doctorate degree and one $(0.9 \%)$ with a bachelor's degree in dental hygiene. The distribution of specialties among the participants was as follows: general dentistry (32.4\%), preventive dental sciences $(24.8 \%)$, conservative dental sciences $(15.2 \%)$, oral and maxillofacial rehabilitation (12.5\%), oral and basic clinical sciences (11.4\%), and DPH (3.8\%). Table 1 shows the baseline characteristics of the respondents.

The descriptive statistics of responses to questions on knowledge about DPH, preferred method of gaining knowledge about DPH, need for a master's program in DPH, as well as respondents' perceptions regarding the impact of DPH education on oral health issues in the country are presented in Table 2. Almost all (98.1\%) of the respondents had some knowledge about DPH. The most preferred method to gain knowledge about DPH reported by respondents was seminar series (47.6\%) followed by workshop (43.8\%), a certificate program (21.9\%), and a master's degree program (17.1\%). The participants were questioned about the impact of DPH education on several oral

Table I Descriptive statistics of study participants $(\mathrm{N}=105)$

\begin{tabular}{ll}
\hline Characteristics & $\mathbf{N}(\%)$ \\
\hline Age & \\
$<30$ years & $47(45.6)$ \\
30 to $<40$ years & $26(25.2)$ \\
$\geq 40$ years & $30(29.1)$ \\
Missing & 2 \\
Gender & \\
Male & $60(57.1)$ \\
Female & $45(42.9)$ \\
Qualifications & \\
Bachelor's in dental sciences & $50(47.6)$ \\
Master's & $23(21.9)$ \\
Doctorate & $3 \mathrm{I}(29.5)$ \\
Other & $\mathrm{I}(0.95)$ \\
Primary appointment/position & \\
Dental faculty & $44(41.9)$ \\
Demonstrator & $20(20.4)$ \\
Consultant & $7(6.7)$ \\
General practitioner & $\mathrm{I}(0.95)$ \\
Intern & $32(30.5)$ \\
Dental hygienist & $\mathrm{I}(0.95)$ \\
Specialty & \\
Conservative dental sciences & $16(15.2)$ \\
Oral and maxillofacial rehabilitation & $12(12.5)$ \\
Preventive dental sciences & $26(24.8)$ \\
Oral and basic clinical sciences & $1 \mathrm{I}(1 \mathrm{I} .4)$ \\
Dental public health & $4(3.8)$ \\
General dentistry & $34(32.4)$ \\
Missing & $2(1.9)$ \\
\hline Abreviation: N, num
\end{tabular}

Abbreviation: $\mathrm{N}$, number.
Table 2 Knowledge, attitude, and perception regarding DPH education $(\mathrm{N}=105)$

\begin{tabular}{ll}
\hline & N (\%) \\
\hline Knowledge of DPH & $103(98 . I)$ \\
Yes & $2(1.9)$ \\
No & \\
Need for developing a master's program in DPH & $69(66.4)$ \\
Strongly agree & $31(29.8)$ \\
Agree & $2(1.9)$ \\
Disagree & $2(1.92)$ \\
Strongly disagree & I (0.95) \\
Missing & \\
Preferred method of gaining DPH knowledge ${ }^{\dagger}$ & $18(17.1)$ \\
Master's degree program & $23(21.9)$ \\
Certificate program & $46(43.8)$ \\
Workshop & $50(47.6)$ \\
Seminar series & $1(1.0)$ \\
Don't know & Average score* \\
\hline & \\
\hline Impact of DPH education & 3.7 \\
Promotion of oral health & 3.6 \\
Delivery of oral health care services & 3.5 \\
Prevalence of oral diseases in the Kingdom & 3.7 \\
Research in the field of dental public health & 3.4 \\
Oral health care policy decisions & \\
\hline
\end{tabular}

Notes: *Scores: I = strongly disagree, 2 = disagree, 3 = agree, 4 = strongly agree; ${ }^{\dagger} \mathrm{N}$ is $>105$ because participants checked more than one answer.

Abbreviations: DPH, dental public health; $\mathrm{N}$, number.

health-related topics. According to the survey participants, a DPH education will have an almost equal impact on the promotion of oral health, the delivery of oral health care services, the prevalence of oral diseases in the Kingdom, research in the field of DPH, and oral health care policy decisions. The average Likert score ranged from 3.4 to 3.7. Finally, $95.1 \%$ of the participants agreed that a master's program in DPH was necessary. A total of 69 out of 105 participants (66.4\%) answered "strongly agree," while 31 (29.8\%) answered “agree." Only four strongly disagreed or disagreed with the need for developing a master's in DPH at KAUFD.

The participants' educational preferences for a DPH master's program are presented in Table 3. They were asked to rank the most preferred teaching material useful for the master's program in DPH from a list of options which included textbooks, instructor slides (content), collection of examples, workbook of homework problems, solution guide to homework problems, database of test questions, and a list of discussion topics. The "collection of examples" and the "list of discussion topics" each received the highest score (3.5), whereas "database of test questions" received the lowest score (2.9) as the preferred methods and strategies for teaching a master's in DPH. The range of responses for each method/strategy of teaching is presented in Figure 1. The most 
Table 3 Respondents' educational preferences for a DPH master's program

\begin{tabular}{lc}
\hline & Average score* \\
\hline Preferred method of teaching instruction & \\
Textbook & 3.4 \\
Instructor slides (content) & 3.3 \\
Collection of examples & 3.5 \\
Workbook of homework problems & 3.3 \\
Solution guide to homework problems & 3.2 \\
Database of test questions & 2.9 \\
List of discussion topics & 3.5 \\
Preferred method of delivery of instructions & \\
Exclusively face-to-face classroom activities & 2.7 \\
Emphasize face-to-face classroom activities & 3.3 \\
with online readings and assignments & \\
Half online activities and half classroom activities & 3.0 \\
Emphasize online activities with classroom meetings & 2.6 \\
Entirely online (class never meets face-to-face) & 1.6 \\
Prerequisite education for DPH master's program \\
Bachelor's degree in dental surgery & 3.5 \\
Dental hygiene degree & 2.7 \\
Bachelor's in medicine and surgery & 2.7 \\
Any bachelor's degree & 2.1 \\
\hline Notes Scor: I stongy dign
\end{tabular}

Notes: *Scores: I = strongly disagree, 2 = disagree, 3 = agree, $4=$ strongly agree. Abbreviation: DPH, dental public health.

preferred method of delivery of a master's in DPH course instructions was mainly face-to-face classroom activities with online readings and assignments (average score $=3.3$ ) as compared to half online activities and half classroom activities (average score $=3.0$ ), exclusive face-to-face classroom activities (average score $=2.7$ ), and mainly online activities with classroom meetings (average score $=2.6$ ). The majority of respondents were not in favor of an exclusively online (class never meets face-to-face) delivery method (average score of 1.6). The range of responses for each delivery method is presented in Figure 2. The most preferred prerequisite qualifications for DPH master's degree students was having a Bachelor of Dental Science (average score $=3.5$ ), followed by a bachelor's degree in medicine and surgery (average score $=2.7$ ) or dental hygiene (average score $=2.7$ ), with the lowest score for a bachelor's degree in any other field (average score $=2.1$ ).

We compared relationships between gender and age categories with response scores for questions on type of program preferred, preferred method of instruction, preferred method of delivery of instructions, and prerequisite education for DPH master's students using proportional odds ratios. Results of the analysis found significant difference among both males and females in terms of their preferences for one of the four preferred methods to gain DPH knowledge. Women were less likely to prefer the choice of a master's degree program (odds ratio $=0.2 ; 95 \%$ confidence interval $=0.1-0.7$ ) as compared to men (Table 4 ). There were no significant differences between men and women for preferred method of instruction, method of delivery of instructions, or prerequisite education. Comparison among the two age categories $(<30$ years and $\geq 30$ years of age) found no significant differences among the two groups across most of the variables evaluated except for five of the options, which significantly differed

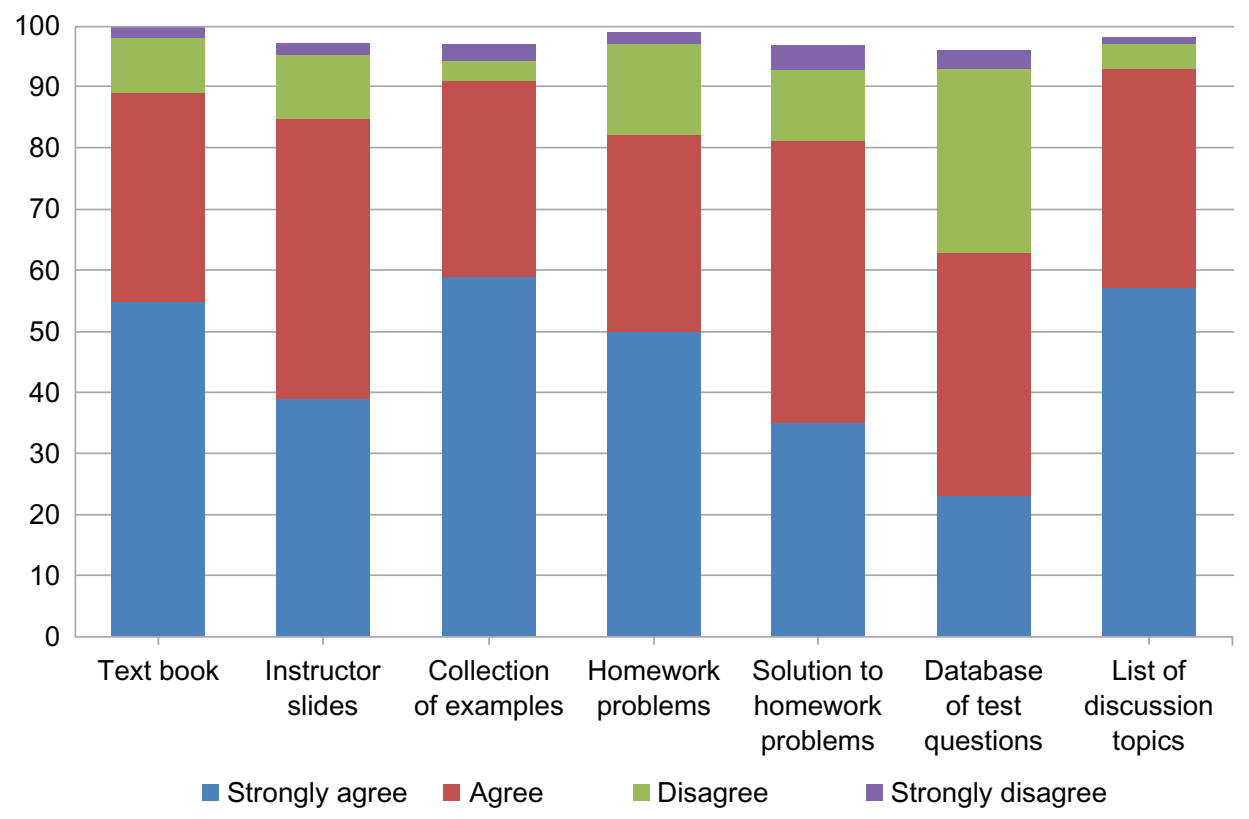

Figure I Preferred teaching materials for a DPH master's program. Abbreviation: DPH, dental public health. 


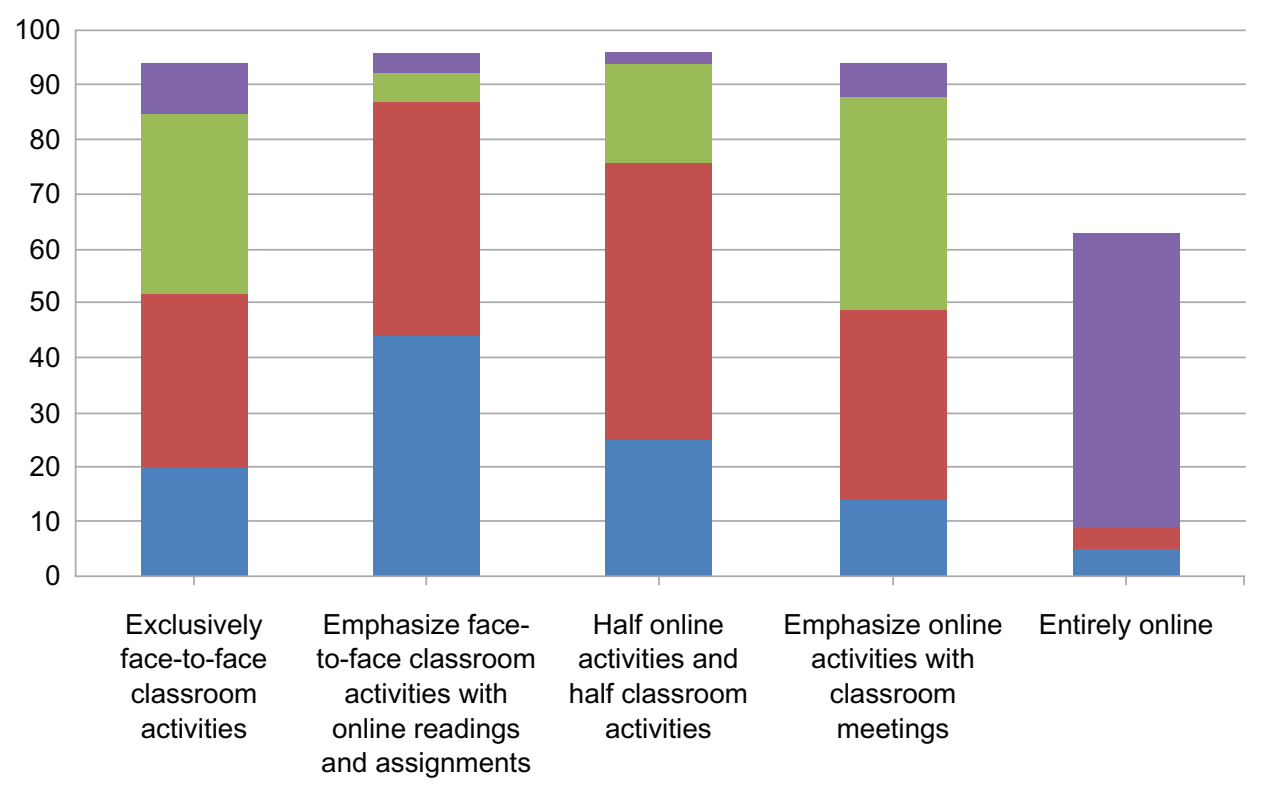

$\square$ Strongly agree $\quad \square$ Agree $\quad$ Disagree $\quad$ Strongly disagree

Figure 2 Preferred method of delivery of DPH master's courses.

Abbreviation: DPH, dental public health.

Table 4 Comparisons of scores for preferred method of knowledge, preferred method of instruction, delivery of instructions, and prerequisite education for DPH by gender

\begin{tabular}{|c|c|c|c|c|c|c|}
\hline & $\begin{array}{l}\text { Female } \\
\mathbf{N}=75^{\dagger}\end{array}$ & $\begin{array}{l}\text { Male* } \\
\mathbf{N}=63^{\dagger}\end{array}$ & $\begin{array}{l}\text { Odds } \\
\text { ratio }\end{array}$ & \multicolumn{2}{|c|}{$\begin{array}{l}\text { 95\% confidence } \\
\text { intervals }\end{array}$} & $P$-value \\
\hline \multicolumn{7}{|l|}{ Preferred method of DPH knowledge } \\
\hline Master's degree program (yes) & 5 & 13 & 0.2 & 0.1 & 0.7 & $0.006^{\#}$ \\
\hline Certificate program (yes) & 9 & 14 & 0.4 & 0.2 & 1.0 & 0.0523 \\
\hline Workshop (yes) & 27 & 19 & I.I & 0.5 & 2.4 & 0.7765 \\
\hline Seminar series (yes) & 33 & 17 & 2.0 & 0.9 & 4.4 & 0.0804 \\
\hline \multirow[t]{2}{*}{ Don't know (yes) } & 1 & 0 & & & & \\
\hline & $\mathbf{N}$ (mean) & $\mathbf{N}$ (mean) & & & & \\
\hline \multicolumn{7}{|l|}{ Preferred method of instruction } \\
\hline Textbook & $57(3.5)$ & $43(3.3)$ & 0.5 & 0.1 & 1.6 & 0.2228 \\
\hline Instructor slides (content) & $56(3.3)$ & $42(3.4)$ & 0.7 & 0.2 & 1.9 & 0.4465 \\
\hline Collection of examples & $57(3.5)$ & $40(3.5)$ & 0.7 & 0.2 & 2.1 & 0.4753 \\
\hline Workbook of homework problems & $57(3.4)$ & $42(3.2)$ & 0.4 & 0.1 & 1.4 & 0.1513 \\
\hline Solution guide to homework problems & $58(3.2)$ & $39(3.2)$ & 1.3 & 0.4 & 3.9 & 0.6551 \\
\hline Database of test questions & $56(2.8)$ & $40(2.9)$ & 1.3 & 0.5 & 3.8 & 0.6180 \\
\hline List of discussion topics & $55(3.5)$ & $43(3.5)$ & 2.0 & 0.6 & 6.4 & 0.2565 \\
\hline \multicolumn{7}{|l|}{ Preferred method of delivery of instructions } \\
\hline Exclusively face-to-face classroom activities & $55(2.6)$ & $39(2.8)$ & 1.5 & 0.7 & 3.1 & 0.306 \\
\hline $\begin{array}{l}\text { Emphasize face-to-face classroom activities with online } \\
\text { readings and assignments }\end{array}$ & $57(3.3)$ & $39(3.4)$ & 1.2 & 0.5 & 2.6 & 0.693 \\
\hline Half online activities and half classroom activities & $56(3.1)$ & $40(3.0)$ & 0.9 & 0.4 & 2.1 & 0.895 \\
\hline Emphasize online activities with classroom meetings & $54(2.5)$ & $40(2.8)$ & 1.8 & 0.8 & 3.9 & 0.131 \\
\hline Entirely online (class never meets face-to-face) & $54(1.5)$ & $38(1.7)$ & 1.2 & 0.5 & 2.8 & 0.615 \\
\hline \multicolumn{7}{|l|}{ Prerequisite education } \\
\hline Bachelor's degree in dental surgery & $59(3.5)$ & $44(3.5)$ & 0.9 & 0.4 & 1.9 & 0.697 \\
\hline Dental hygienist & $58(2.6)$ & $41(2.8)$ & 1.7 & 0.8 & 3.7 & 0.169 \\
\hline Bachelor's in medicine and surgery & $58(2.6)$ & $42(2.8)$ & 1.6 & 0.7 & 3.2 & 0.242 \\
\hline Any bachelor's degree & $58(2.0)$ & $40(2.1)$ & 1.1 & 0.5 & 2.4 & 0.744 \\
\hline
\end{tabular}

Notes: *Males are the referent category; total is more than total number of female and male participants because participants checked more than one answer; " significant.

Abbreviations: DPH, dental public health; $\mathrm{N}$, number. 
between the two (Table 5). Participants below 30 years of age were more likely to prefer a certificate program to gain DPH knowledge (odds ratio $=2.9 ; 95 \%$ confidence interval $=1.1-7.7)$; were more likely to have a lower score for use of textbooks and workbook of homework problems; and were more likely to have a lower score for a preference of a Bachelor of Dental Science as a prerequisite education as compared to those 30 years and above. Moreover, the participants under 30 years of age were less likely to have a lower score for exclusive face-to-face classroom activities.

The participants' ranking of the knowledge, skills, and abilities that they perceive as most needed by DPH practitioners are presented in Table 6. All the skills listed were ranked as very important or important. The least average scores were given to skills such as negotiation abilities, political sense, and having knowledge about computers and informatics (average score $=4.2$ ). Maximum scores were given to knowledge of clinical dentistry and public health (average score $=4.7$ ), ability to work effectively with a multidisciplinary team (average score $=4.7$ ), and ethical considerations (average score $=4.9$ ).

Finally, the participants were asked to assess their own level of competency across ten DPH competencies identified by the AAPHD. The participants were also asked to rank the importance of each of these competencies in their own work. Table 7 provides the average score for self-assessment and ranking across the ten competencies listed. The results of the self-assessment of competencies found that most participants considered themselves as having a moderate amount of experience and basic range of knowledge of DPH practices and competencies, with average scores ranging between 2.6 and 3.9. The participants were most competent in incorporating ethical standards in oral health programs and activities (average score $=3.9$ ), criticizing and synthesizing scientific literature (average score $=3.9$ ), and communicating and collaborating with

Table 5 Comparisons of scores for preferred method of knowledge, preferred method of instruction and delivery of instructions, as well as prerequisite education for DPH by age

\begin{tabular}{|c|c|c|c|c|c|c|}
\hline & $\begin{array}{l}<\mathbf{3 0} \text { years } \\
\mathbf{N}=\mathbf{5 7 ^ { \dagger }}\end{array}$ & $\begin{array}{l}\geq 30 \text { years* } \\
\mathbf{N}=6^{\dagger}\end{array}$ & Odds ratio & \multicolumn{2}{|c|}{$\begin{array}{l}95 \% \text { confidence } \\
\text { intervals }\end{array}$} & $P$-value \\
\hline \multicolumn{7}{|l|}{ Preferred method of DPH knowledge } \\
\hline Master's degree program & 7 & II & 0.8 & 0.2 & 2.1 & 0.5828 \\
\hline Certificate program & 15 & 8 & 2.9 & I.I & 7.7 & $0.0292^{\#}$ \\
\hline Workshop & 21 & 25 & I.I & 0.5 & 2.3 & 0.8713 \\
\hline Seminar series & 13 & 25 & 0.9 & 0.4 & 2.0 & 0.8810 \\
\hline \multirow[t]{2}{*}{ Don't know } & 1 & 0 & & & & \\
\hline & $\mathbf{N}$ (mean) & $\mathbf{N}$ (mean) & & & & \\
\hline \multicolumn{7}{|l|}{ Preferred method of instruction } \\
\hline Textbook & $44(3.0)$ & $56(3.8)$ & 9.5 & 3.9 & 23.0 & $<0.000 \mathrm{I}^{\#}$ \\
\hline Instructor slides (content) & $44(3.4)$ & $53(3.3)$ & 0.8 & 0.4 & 1.8 & 0.3567 \\
\hline Collection of examples & $43(3.5)$ & $54(3.5)$ & 0.7 & 0.3 & 1.6 & 0.1597 \\
\hline Workbook of homework problems & $44(3.0)$ & $55(3.6)$ & 4.0 & 1.8 & 8.9 & $0.0006^{\#}$ \\
\hline Solution guide to homework problems & $44(3.0)$ & $53(3.3)$ & 1.8 & 0.8 & 3.8 & 0.1387 \\
\hline Database of test questions & $44(2.8)$ & $52(2.9)$ & 1.3 & 0.6 & 2.8 & 0.8415 \\
\hline List of discussion topics & $43(3.4)$ & $55(3.6)$ & 2.1 & 1.0 & 4.8 & 0.0637 \\
\hline \multicolumn{7}{|l|}{ Preferred method of delivery of instructions } \\
\hline Exclusively face-to-face classroom activities & $45(3.0)$ & $49(2.4)$ & 0.3 & 0.1 & 0.7 & $0.0023^{\#}$ \\
\hline Emphasize face-to-face classroom activities & $44(3.2)$ & $52(0.4)$ & 1.8 & 0.8 & 3.9 & 0.1451 \\
\hline \multicolumn{7}{|l|}{ with online readings and assignments } \\
\hline Half online activities and half classroom activities & $43(3.1)$ & $53(3.0)$ & 0.7 & 0.3 & 1.6 & 0.4309 \\
\hline Emphasize online activities with classroom meetings & $44(2.6)$ & $50(2.6)$ & 1.0 & 0.5 & 2.2 & 0.9121 \\
\hline Entirely online (class never meets face-to-face) & $43(1.7)$ & $49(1.5)$ & 0.7 & 0.3 & 1.6 & 0.4492 \\
\hline \multicolumn{7}{|l|}{ Prerequisite education } \\
\hline Bachelor's degree in dental surgery & $46(3.2)$ & $57(3.7)$ & 3.6 & 1.5 & 8.3 & $0.003^{\#}$ \\
\hline Dental hygienist & $45(2.7)$ & $54(2.7)$ & 1.0 & 0.5 & 2.2 & 0.93 \\
\hline Bachelors' in medicine and surgery & $45(2.5)$ & $54(2.8)$ & 1.8 & 0.8 & 3.6 & 0.132 \\
\hline Any bachelor's degree & $45(2.2)$ & $53(2.0)$ & 0.7 & 0.3 & 1.4 & 0.3117 \\
\hline
\end{tabular}

Notes: $* \geq 30$ years of age is the referent category; total is more than total number of female and male participants because participants checked more than one answer; "statistically significant.

Abbreviations: DPH, dental public health; N, number. 
Table 6 Skills, knowledge, or abilities most needed by DPH practitioners

\begin{tabular}{ll}
\hline & $\begin{array}{l}\text { Average } \\
\text { score* }\end{array}$ \\
\hline Knowledge of clinical dentistry and public health & 4.7 \\
Leadership abilities, communication skills, and both oral & 4.6 \\
and written interpersonal skills & \\
Ability to work effectively with a multidisciplinary team & 4.7 \\
Coalition and constituency building; advocacy skills & 4.2 \\
Negotiation abilities; political savvy; problem solving; & 4.2 \\
computers, technology, and informatics; marketing & \\
Use of media in health promotion; research skills; & 4.5 \\
administrative skills; assessment, policy development, & \\
and assurance & \\
Health delivery systems; financing mechanisms; & 4.2 \\
evidence-based dentistry, grantsmanship; fundraising & \\
Ethics & 4.9
\end{tabular}

Notes: *Scores: 5 = very important, $4=$ important, $3=$ moderately important, 2 = of little importance, I = unimportant.

Abbreviation: DPH, dental public health.

groups and individuals on oral health issues (average score $=3.9$ ). They scored least on competencies related to advocating for, implementation of, and evaluation of public health policy (average score $=2.6$ ); designing and understanding the use of surveillance systems to monitor oral health (average score $=2.7$ ); and developing resources, as well as implementing and managing oral health programs for populations (average score $=3.0$ ). Overall, the average score for self-assessment did not exceed the average mean of four. Most participants ranked the competencies as important for their work except for "design and understand the use of surveillance systems to monitor oral health," which they ranked as moderately important.

To test for differences between younger and older dental professionals, we modeled self-competency scores across the two age categories $(<30$ years and $\geq 30$ years of age). The results found that participants in the younger age category $(<30$ years) were consistently more likely to have lower scores of self-assessed DPH competencies compared to those in the older age group (Table 8).

\section{Discussion}

Overall, the collected data emphasize the need for initiating a DPH program. The results indicated that the majority $(95 \%)$ of participants agreed that it is necessary to offer a master's degree program in DPH at KAUFD. They believed that a master's program in DPH will have an impact on the promotion of oral health, the delivery of oral health services, prevalence of oral diseases, research in oral public health, and oral health care policy decisions in the country.

These same participants who reported a need for a master's program at KAUFD indicated a preference for seminar series or workshops to gain knowledge about DPH. Though these results may at first seem contradictory, at second glance, they are not. Our study population is comprised mainly of faculty members and specialists who work in academic positions and hold master's and doctorate degrees in specific fields of dentistry. They acknowledge the need for a master's education in DPH in their institute specifically and in the country in general. However, as far as their own academic/

Table 7 Assessment and ranking of DPH competencies

\begin{tabular}{lll}
\hline & Average score & \multicolumn{1}{c}{$\begin{array}{l}\text { Ranking importance } \\
\text { of competencies }\end{array}$} \\
\cline { 2 - 3 } & $\begin{array}{l}\text { Self-competency } \\
\text { assessment* }\end{array}$ & 4.1 \\
\hline Plan oral health programs for populations & 3.1 & 4.2 \\
Select interventions and strategies for the prevention and control of oral diseases & 3.5 & 4.0 \\
and promotion of oral health & 3.0 & 4.2 \\
Develop resources, implement, and manage oral health programs for populations & 3.9 & 4.1 \\
Incorporate ethical standards in oral health programs and activities & 3.4 & 3.9 \\
Evaluate and monitor dental care delivery systems & 2.7 & 4.2 \\
Design and understand the use of surveillance systems to monitor oral health & 3.9 & 4.1 \\
Communicate and collaborate with groups and individuals on oral health issues & 2.6 & \\
Advocate for, implement, and evaluate public health policy, legislation, and regulations & & 4.2 \\
to protect and promote the public's oral health & 3.9 & 4.2 \\
Critique and synthesize scientific literature & 3.4 & \\
Design and conduct population-based studies to answer oral and public health questions & & \\
\hline
\end{tabular}

Notes: *Scores 1-2: Developing awareness/building knowledge; limited repertoire; limited experience; unaware of potential problems; unaware of questions to ask. Scores 3-4: Applying knowledge routinely; basic repertoire; moderate amount of experience; solves problems as they arise; aware of questions to ask and able to access resources to answer the questions. Score 5-6: Using knowledge fluently and effectively; advanced repertoire; extensive experience; anticipates problems before they arise; poses questions to the field; sought input. ${ }^{\dagger} 5=$ very important, 4 = important, 3 = moderately important, $2=$ of little importance, I = unimportant. Abbreviation: DPH, dental public health. 
Table 8 Comparison of self-competency assessment of DPH competencies by age

\begin{tabular}{|c|c|c|c|c|c|}
\hline & \multicolumn{2}{|c|}{$\begin{array}{l}\text { Self-competency } \\
\text { assessment* }\end{array}$} & \multicolumn{3}{|c|}{$<\mathbf{3 0}$ years } \\
\hline & $\begin{array}{l}<30 y \\
(N=16)\end{array}$ & $\begin{array}{l}\geq 30 y \\
(N=37)\end{array}$ & $\begin{array}{l}\text { Odds } \\
\text { ratio }\end{array}$ & $95 \% \mathrm{Cl}$ & $P$-value \\
\hline Plan oral health programs for populations & 2.4 & 3.4 & 3.9 & I.9-8.1 & 0.0003 \\
\hline $\begin{array}{l}\text { Select interventions and strategies for the prevention and control of oral } \\
\text { diseases and promotion of oral health }\end{array}$ & 2.6 & 3.7 & 4.9 & $2.3-10.5$ & $<0.0001$ \\
\hline Develop resources, implement, and manage oral health programs for populations & 2.2 & 3.3 & 4.7 & $2.2-9.9$ & $<0.0002$ \\
\hline Incorporate ethical standards in oral health programs and activities & 3.1 & 4.0 & 3.3 & $1.6-6.9$ & 0.0013 \\
\hline Evaluate and monitor dental care delivery systems & 2.7 & 3.6 & 4.1 & $1.9-8.7$ & 0.0002 \\
\hline Design and understand the use of surveillance systems to monitor oral health & 2.2 & 3.0 & 2.9 & $1.4-6.1$ & 0.0035 \\
\hline Communicate and collaborate with groups and individuals on oral health issues & 3.2 & 4.0 & 3.3 & $1.6-6.8$ & 0.0013 \\
\hline $\begin{array}{l}\text { Advocate for, implement, and evaluate public health policy, legislation, } \\
\text { and regulations to protect and promote the public's oral health }\end{array}$ & 2.0 & 3.0 & 4.4 & $2.1-9.3$ & 0.0001 \\
\hline Critique and synthesize scientific literature & 2.4 & 4.6 & 26.8 & $10.3-70.1$ & $<0.0001$ \\
\hline $\begin{array}{l}\text { Design and conduct population-based studies to answer oral and public } \\
\text { health questions }\end{array}$ & 2.4 & 3.7 & 6.3 & $2.9-13.7$ & $<0.0001$ \\
\hline
\end{tabular}

Notes: 30 years of age is the referent category. *Score I-2: developing awareness/building knowledge; limited repertoire; limited experience; unaware of potential problems; unaware of questions to ask. Score 3-4: applying knowledge routinely; basic repertoire; moderate amount of experience; solves problems as they arise; aware of questions to ask and able to access resources to answer the questions. Score 5-6: using knowledge fluently and effectively; advanced repertoire; extensive experience; anticipates problems before they arise; poses questions to the field; sought input. Abbreviations: DPH, dental public health; N, number.

professional needs, they prefer to gain specific knowledge and skills in DPH pertinent to their field of specialty through less intensive programs.

The need for a master's program in DPH is further supported by the results of the self-assessed competency level for DPH competencies identified by AAPHD, which ranged from 2.5 to 4 . These results suggest that most participants considered themselves as having moderate amounts of experience and a basic range of knowledge of DPH practices and competencies, thus identifying a need for a structured education in DPH. In addition, the average ranking of importance of DPH competencies was more than 4 , indicating that the dental professionals considered these competencies important in their field of work.

The results of the levels of DPH competencies among various dental professionals and the importance that they gave to individual competencies will help in designing course structures, as it will allow course objectives to be focused in areas where the competency levels are lower and importance is ranked higher. The survey also provides insights on the preferred teaching materials and mode of instruction in a master's degree program. Since there was an overall agreement on using all the methods of teaching materials including textbooks, instructor slides, and homework, the graduate-level course needs to be structured using a combination of all of these teaching methods. Based on the analyzed data, it is recommended that a graduate course in DPH is delivered either by traditional means (exclusively face-to- face instruction) or in a hybrid form, which emphasizes face-to-face classroom activities, but combines those with online readings and assignments. Furthermore, considering the high rate of disagreement, it is not recommended that an entirely online format be used for course delivery. These results, however, limit the options of distance learning education for practitioners who may not have adequate time to attend classes because of their busy schedules. It is possible that the expansion of the survey to include general or private practitioners may provide alternative insights on distance learning for DPH. An online format of teaching has several advantages such as offering flexibility to the students in terms of time and schedule, reducing costs for conducting courses, increasing accessibility, and reaching out to an untapped student pool. On the other hand, familiarity of the target population with internet skills and limited options for group activities may be possible disadvantages, particularly in a master's program. ${ }^{10}$

In general, a structured master's program is essential to master DPH competencies; it is the foundation of DPH education and practice. Interestingly, the significant odds of having lower DPH competency scores in the younger age group ( $<30$ years) compared to the older age group ( $\geq 30$ years) across all of the DPH competencies (Table 8 ) indicate that there is a potential pool of students for a master's program in DPH.

Among the strengths of this survey are its large sample size and high response rate. A limitation of the survey is 
that it does not include general practitioners and public health officials outside of KAUFD. However, based on the preliminary results and several recommendations from the participants regarding preferred methods of instruction, as well as certain skills and competencies, we plan to modify the survey and extend the survey to include a larger population across the country.

\section{Conclusion}

This needs assessment survey has helped assess the overall opinions on the need for a graduate program in DPH at KAUFD. It is a preliminary step in the formative planning of a well-structured program, which will address the needs and gaps in oral public health in the country, and will inform the development of course content for the master's program.

\section{Acknowledgments}

I would like to express my thanks and appreciation to Dr Heba Alkarimi, Dr Mohammad J Alzahrani, and Dr Samar Mashabi for their valuable comments on the questionnaire design and final report. A big salute to all of the dental professionals who participated in the survey and contributed to the DPH program needs assessment.

\section{Disclosure}

The author declares no conflicts of interest in this work.

\section{References}

1. American Association of Public Health Dentistry. Competency statements for dental public health [homepage on the internet]. Springfield: American Association of Public Health Dentistry; 2004. Available from: http://www.aaphd.org/default.asp?page=competencies.htm. Accessed October 1, 2012.

2. National Public Health Performance Standards Program. Atlanta, GA, USA. 10 Essential Public Health Services. 2010. Available at http://www. cdc.gov/nphpsp/essentialservices.html. Accessed October 1, 2012.

3. Fink D. A Self-Directed Guide to Designing Courses for Significant Learning. San Francisco: Jossey-Bass, 2003. Available at http://trc. virginia.edu/Workshops/2004/Fink_Designing_Courses_2004.pdf. Accessed on September 19, 2012.

4. Grier AS. Integrating needs assessment into career and technical curriculum development. Journal of Industrial Teacher Education. 2005;42(1):59-66.

5. Weintraub JA. The development of competencies for specialists in dental public health. J Public Health Dent. 1998;58 Suppl 1:114-118.

6. Centers for Disease Control and Prevention (CDC), Association for Prevention Teaching and Research (APTR). Competencies-to-Curriculum Toolkit. Columbia University, New York, NY, USA. Centers for Disease Control and Prevention, Association for Prevention Teaching and Research; 2008. Available from: http://www.asph.org/userfiles/Competency-to-Curriculum-Toolkit08.pdf. Accessed September 12, 2012.

7. Steinert Y, Mann K, Centeno A, et al. A systematic review of faculty development initiatives designed to improve teaching effectiveness in medical education: BEME Guide No 8. Med Teach. 2006; 28(6):497-526.

8. Zhang Q, Reisslein J, Klein J, Reisslein M. A needs assessment for a graduate level course in optical networking. Proceedings of the Education and Training in Optics and Photonics Conference; October 6-9, 2003; Tucson, AZ, USA.

9. Ghere G, King JA, Stevahn L, Minnema J. A professional development unit for reflecting on program evaluator competencies. Am J Eval. 2006;27(1):108-123.

10. Serlin R. The Advantages and Disadvantages of Online Courses. Location: Publisher; 2005. Available from: http://www.gened.arizona. edu/sites/default/files/AdvantagesDisadvantagesOnlineCourses.pdf. Accessed January 20, 2013. 


\section{Supplmentary material \\ Needs Assessment Survey Template}

\section{Needs assesment survey}

King Abdulaziz University Faculty of Dentistry 2013

\section{Division of Community Dentistry Department of Preventive Dental Sciences}

\section{Competency Assessment Survey}

The Faculty of Dentistry at King Abdulaziz University is developing a Master's of Science program in Dental Public health. In order to design a comprehensive program, it is essential to understand the level of dental public health expertise existing in the country and to identify needs and gaps that will further strengthen these skills. The attached needs assessment survey will help us to gather this information. We request that you take some time to share your information, ideas, needs and concerns. All information provided by you will remain confidential. The data from the survey will be analyzed in an aggregate form.

Competencies are defined as follows:

\begin{tabular}{lll} 
Term & Definition & Purpose \\
\hline Competencies & $\begin{array}{l}\text { An integrated set of } \\
\text { knowledge, skills }\end{array}$ & $\begin{array}{l}\text { Describe the expectation of a job } \\
\text { performance and for evaluation } \\
\text { and attitudes that } \\
\text { supports successful } \\
\text { performance in job } \\
\text { position }\end{array}$ \\
\end{tabular}

\section{Survey participants}

Survey participants are expected to be representative of the stakeholders who will participate and/or benefit from this program. Please insert a check mark $(\checkmark)$ next to the item/ items that best describe your current position:

- Dental Faculty

- Public Health Official

- Interns and newly graduated dentists

- Public health dental practitioner

- Private dental practitioner

- Other (please specify)

\section{Instructions for Completing Survey}

Please complete each section of the survey. You will begin with information about yourself (name optional), job title, department/division and qualifications). Space is provided on the top of each page for your initials. At the end, we have provided space for you to write any additional thoughts and concerns that you may have.

\section{Needs assessment survey}

NAME: (Optional)

JOB TITLE:

DEPARTMENT/DIVISION:

INSTITUTION:

SEX:

AGE GROUP: $20+/ 30+/ 40+/ 50+$

QUALIFICATIONS: (Please List All)

DATE: $1-1$

\section{Introduction}

Dental Public Health is the science and art of preventing and controlling dental diseases and promoting dental health through organized community efforts.

Public health dentists promote oral health by:

- Assessing the oral health needs of the community

- Developing and implementing oral health policy

- Providing programs and services that address oral health issues.

Many dentists work within public health settings to enhance the traditional DPH infrastructure. Many do so without formal public health training. These public health settings include, but are not limited to: city, province and region health departments; correctional facilities; nursing and other long-term care facilities for the elderly and those with various disabilities; school-based health programs; and free and/or volunteer clinics.

The Core Public Health Functions Steering Committee developed the framework for the Essential Services in 1994. This steering committee included representatives from US Public Health Service agencies and other major public health organizations. The Essential Services provide a working definition of public health and a guiding framework for the responsibilities of local public health systems:

1. Monitor health status to identify and solve community health problems.

2. Diagnose and investigate health problems and health hazards in the community.

3. Inform, educate, and empower people about health issues.

4. Mobilize community partnerships and action to identify and solve health problems.

5. Develop policies and plans that support individual and community health efforts.

6. Enforce laws and regulations that protect health and ensure safety. 
7. Link people to needed personal health services and assure the provision of health care when otherwise unavailable.

8. Assure competent public and personal health care workforce.

9. Evaluate effectiveness, accessibility, and quality of personal and population-based health services.
10. Research for new insights and innovative solutions to health problems.

11. Based on your experience in the field of dentistry and public health, please answer the following survey questions:

\section{Sr No Questions}

Multiple Choices (Check all that apply) I. Before this survey, did you know what dental public
health is?

2. You will prefer to gain knowledge and skills of dental public health through:

3. Overall, it is necessary to offer a master's degree in dental public health in the school of dentistry at King Abdulaziz University

4. As a course instructor, what kind of materials / strategies would you use to support your teaching?

5. If a master's level course for dental public health is developed, what would be the optimal delivery method for graduate courses

6. The prerequisite knowledge a student should have before being admitted to a master's program in dental public health

7. In your opinion, a master's program in dental public health will have an impact on:

\author{
$\square$ Yes \\ $\square$ No \\ $\square$ Refused to answer \\ $\square$ Master's degree program \\ $\square$ Certificate program \\ $\square$ Workshop \\ Seminar series \\ Don't know \\ Refused to answer \\ SA $\square$ A $\square$ D $\square$ SD
}

- Textbook

- Instructor Slides (Content)

- Collection of Examples

- Workbook of Homework Problems

- Solution Guide to Homework Problems

- Database of Test Questions

- List of Discussion Topics

- Exclusively Face-to-Face Classroom Activities

- Emphasize Face-to-Face Classroom Activities with Online Readings and Assignments

- Half Online Activities and Half Classroom Activities $\square$ SA $\square$ A $\square \square$ DD

- Emphasize Online Activities with Classroom $\quad \square$ SA $\square$ A $\square \square$ SD Meetings

- Entirely Online (Class Never Meets Face-to-Face)

- Bachelor's degree in Dental Surgery

- Dental Hygienist

- Master's in Public Health (MPH)

- Bachelors' in Medicine and Surgery (MBBS)

- Any bachelor's degree

- Promotion of oral health

- Delivery of oral health care services

- Prevalence of oral diseases in the Kingdom

- Research in the field of dental public health

- Oral health care policy decisions

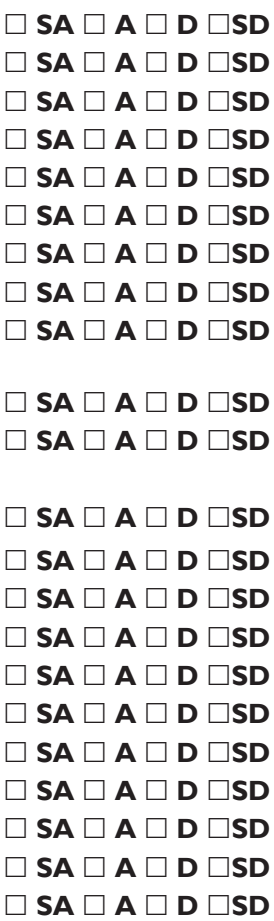

Of the following, rank the list of skills, knowledge, or abilities most needed by dental public health practitioners

8. Knowledge of clinical dentistry and public health

9. Leadership abilities; Communication skills; and both oral and written Interpersonal skills
Very Important Important Moderately Important

Of Little Importance

Unimportant

Very Important Important

Moderately Important Of Little Importance Unimportant 
10. Ability to work effectively with a multidisciplinary team

II. Coalition and constituency building; Advocacy skills

12. Negotiation abilities; Political savvy; Problem solving; Computers, technology, and informatics; Marketing

13. Use of media in health promotion; Research skills; Administrative skills; Assessment, policy development, and assurance

14. Health delivery systems; Financing mechanisms; Evidence-based dentistry; Grantsmanship; Fundraising

15. Ethics
Very Important

Important

Moderately Important

Of Little Importance

$\square$ Unimportant

$\square$ Very Important

$\square$ Important

$\square$ Moderately Important

$\square$ Of Little Importance

Unimportant

$\square$ Very Important

$\square$ Important

$\square$ Moderately Important

Of Little Importance

$\square$ Unimportant

$\square$ Very Important

$\square$ Important

$\square$ Moderately Important

Of Little Importance

$\square$ Unimportant

$\square$ Very Important

$\square$ Important

Moderately Important

Of Little Importance

$\square$ Unimportant

$\square$ Very Important

$\square$ Important

Moderately Important

Of Little Importance

Unimportant

\section{Please use the Self-assessment rating scale and Ranking below in answering the following questions:}

1. Self-assessment rating scale (1-6) has been validated and used extensively by Gail Ghere and colleagues (2006) in a 'program evaluator competencies self-assessment tool' as part of professional development sessions, graduate-level seminars, and introductory program evaluation courses.

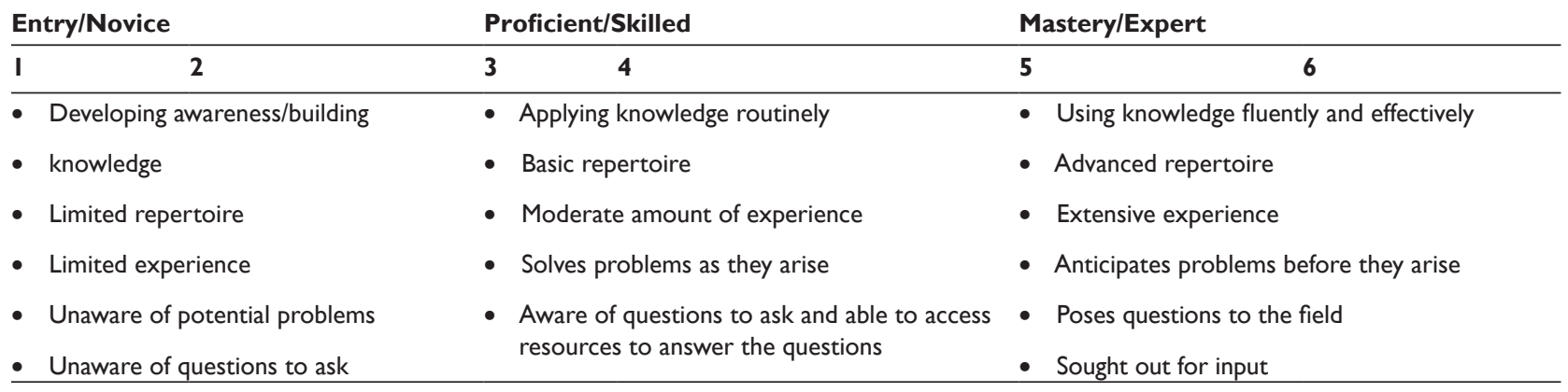

2. Ranking the importance of competency for the training curriculum
A. Very Important
B. Important
C. Moderately Important
D. Of Little Importance
E. Unimportant 
The following is the list of Dental Public Health Competencies. Please assess your own level of competency for each of the following and rate how each competency is important for your work. Your input is very valuable.

\begin{tabular}{|c|c|c|c|c|c|c|c|c|c|c|c|c|}
\hline \multirow[t]{2}{*}{ No } & \multirow[t]{2}{*}{$\begin{array}{l}\text { Dental Public Health } \\
\text { Competencies }\end{array}$} & \multicolumn{6}{|c|}{$\begin{array}{l}\text { Self-assessment of your competency } \\
\text { level ( } I=\text { Entry level } \ldots . . .6 \text { = Expert })\end{array}$} & \multicolumn{5}{|c|}{$\begin{array}{l}\text { Rate how important this competency } \\
\text { is for your work ( } A=\text { Very } \\
\text { important..... E Unimportant) }\end{array}$} \\
\hline & & I & 2 & 3 & 4 & 5 & 6 & $\mathbf{A}$ & B & C & D & $\mathbf{E}$ \\
\hline I. & $\begin{array}{l}\text { Plan oral health programs for } \\
\text { populations. }\end{array}$ & $\square$ & $\square$ & $\square$ & $\square$ & $\square$ & $\square$ & $\square$ & $\square$ & $\square$ & $\square$ & $\square$ \\
\hline 2. & $\begin{array}{l}\text { Select interventions and strategies for } \\
\text { the prevention and control of oral } \\
\text { diseases and promotion of oral health }\end{array}$ & $\square$ & $\square$ & $\square$ & $\square$ & $\square$ & $\square$ & $\square$ & $\square$ & $\square$ & $\square$ & $\square$ \\
\hline 3. & $\begin{array}{l}\text { Develop resources, implement, and } \\
\text { manage oral health programs for } \\
\text { populations }\end{array}$ & $\square$ & $\square$ & $\square$ & $\square$ & $\square$ & $\square$ & $\square$ & $\square$ & $\square$ & $\square$ & $\square$ \\
\hline 4. & $\begin{array}{l}\text { Incorporate ethical standards in oral } \\
\text { health programs and activities }\end{array}$ & $\square$ & $\square$ & $\square$ & $\square$ & $\square$ & $\square$ & $\square$ & $\square$ & $\square$ & $\square$ & $\square$ \\
\hline 5. & $\begin{array}{l}\text { Evaluate and monitor dental care } \\
\text { delivery systems }\end{array}$ & $\square$ & $\square$ & $\square$ & $\square$ & $\square$ & $\square$ & $\square$ & $\square$ & $\square$ & $\square$ & $\square$ \\
\hline 6. & $\begin{array}{l}\text { Design and understand the use of } \\
\text { surveillance systems to monitor oral } \\
\text { health }\end{array}$ & $\square$ & $\square$ & $\square$ & $\square$ & $\square$ & $\square$ & $\square$ & $\square$ & $\square$ & $\square$ & $\square$ \\
\hline 7. & $\begin{array}{l}\text { Communicate and collaborate with } \\
\text { groups and individuals on oral health } \\
\text { issues }\end{array}$ & $\square$ & $\square$ & $\square$ & $\square$ & $\square$ & $\square$ & $\square$ & $\square$ & $\square$ & $\square$ & $\square$ \\
\hline 8. & $\begin{array}{l}\text { Advocate for, implement, and evaluate } \\
\text { public health policy, legislation, and } \\
\text { regulations to protect and promote } \\
\text { the public's oral health }\end{array}$ & e $\square$ & $\square$ & $\square$ & $\square$ & $\square$ & $\square$ & $\square$ & $\square$ & $\square$ & $\square$ & $\square$ \\
\hline 9. & $\begin{array}{l}\text { Critique and synthesize scientific } \\
\text { literature }\end{array}$ & $\square$ & $\square$ & $\square$ & $\square$ & $\square$ & $\square$ & $\square$ & $\square$ & $\square$ & $\square$ & $\square$ \\
\hline 10. & $\begin{array}{l}\text { Design and conduct population-based } \\
\text { studies to answer oral and public } \\
\text { health questions }\end{array}$ & $\square$ & $\square$ & $\square$ & $\square$ & $\square$ & $\square$ & $\square$ & $\square$ & $\square$ & $\square$ & $\square$ \\
\hline
\end{tabular}

Please indicate any additional comments on specific skills/competencies that are necessary but were deficient or missing from the table above.

Thank you for your time.

Advances in Medical Education and Practice

Dovepress

\section{Publish your work in this journal}

Advances in Medical Education and Practice is an international, peerreviewed, open access journal that aims to present and publish research on Medical Education covering medical, dental, nursing and allied healthcare professional education. The journal covers undergraduate education, postgraduate training and continuing medical education including emerging trends and innovative models linking education, research, and healthcare services. The manuscript management system is completely online and includes a very quick and fair peer-review system. Visit http://www.dovepress.com/testimonials.php to read real quotes from published authors.

Submit your manuscript here: http://www.dovepress.com/advances-in-medical-education-and-practice-journal 